\title{
Study of Evaluation of Causes of Male Infertility at a Tertiary Care Hospital
}

\author{
${ }^{1} \mathrm{KM}$ Umashankar, ${ }^{2}$ Joyeeta Mukherjee, ${ }^{3} \mathrm{SN}$ Banerjee, ${ }^{4}$ Ramya Cristy, ${ }^{5} \mathrm{BN}$ Seal, ${ }^{6} \mathrm{CL}$ Drakshyani
}

\begin{abstract}
Introduction: Worldwide 580 million males experience infertility at some point of time in their life; of these, 372 million reside in low- and middle-income countries. Male subfertility is one of the most rapidly growing fields in medicine, with dramatic advances and treatment. If a male infertility factor is present, it is almost always defined by the finding of an abnormal semen analysis, although other male factors may play a role even when the semen analysis is normal.
\end{abstract}

Aims: To classify the causes of male infertility at pre-testicular, testicular, and post-testicular levels.

Materials and methods: This study was conducted at the Department of Obstetrics and Gynecology in collaboration with the Department of Radio Diagnosis, Institute of Postgraduate Medical Education and Research, Kolkata.

Results: Pre-testicular cause was seen in $7 \%$ of patients. Erectile dysfunction is the commonest. In testicular causes, varicocele is the most common (29.6\%), followed by idiopathic $(25.9 \%)$ and trauma in $14.8 \%$, and other causes, such as torsion, infective orchitis, and cryptorchism show a common incidence of $7.4 \%$. In post-testicular, varity in $51.8 \%$ is due to ejaculatory duct obstruction and accessory gland dysfunction, and acquired hernia surgeries have a common incidence of $14.81 \%$. The least common cause is epididymal asthenozoospermia.

Conclusion: In male infertility evaluation history and clinical examination, semen analysis is the common tool for all groups of patients. Pre-testicular male infertile is mainly due to consequences of primary or secondary dysfunction of endocrine or exocrine glands influencing the male reproductive axis. Testicular group of male infertility are due to varity of genetic, congenital, and acquired insults to the proper testicular function; post-testicular cause of infertility is due to pathology in the pathway of sperm passage; this is influenced by congenital and acquired defects and diseases respectively. The idiopathic group of patients needs further evaluation by use of advanced seminal tests like immunological tests, semen culture, special staining of the spermatozoa, sperm DNA integrity tests, appropriate genetic evaluation and. Evaluation of ultrastructural abnormalities of spermatozoa, for detection of defects in outer dense fibers, microtubules, mitochondria, connecting piece, and acrosome.

Keywords: Male infertility, Post-testicular, Pre-testicular, Testicular.

\footnotetext{
${ }^{1}$ Assistant Professor, ${ }^{2}$ Clinical Tutor, ${ }^{3}$ Associate Professor ${ }^{4}$ Resident, ${ }^{5}$ Professor, ${ }^{6}$ Junior Resident

${ }^{1}$ Department of Obstetrics and Gynecology, MVJ Medical College and Research Hospital, Bengaluru, Karnataka, India

${ }^{2}$ Department of Obstetrics and Gynecology, College of Medicine \& J.N.M. Hospital, Kalyan, Nadia, West Bengal, India

${ }^{3-6}$ Department of Obstetrics and Gynecology, IPGMER, Kolkata West Bengal, India

Corresponding Author: KM Umashankar, Assistant Professor Department of Obstetrics and Gynecology, MVJ Medical College and Research Hospital, Bengaluru, Karnataka, India, Phone: +919986909374, e-mail: ukumashankar@gmail.com
}

How to cite this article: Umashankar KM, Mukherjee J, Banerjee SN, Cristy R, Seal BN, Drakshyani CL. Study of Evaluation of Causes of Male Infertility at a Tertiary Care Hospital. J South Asian Feder Obst Gynae 2016;8(2):113-122.

Source of support: Nil

Conflict of interest: None

Date of received: 17 Nov 2015

Date of acceptance: 10 Feb 2016

Date of publication: April 2016

\section{INTRODUCTION}

Worldwide 580 million men experience infertility at some point of time in their life; of these, 372 million reside in low- and middle-income countries. ${ }^{1}$ Male subfertility is one of the most rapidly growing fields in medicine, with dramatic advances and treatment. If a male infertility factor is present, it is almost always defined by the finding of an abnormal semen analysis, although other male factors may play a role even when the semen analysis is normal. While the patient's semen may seem to be the target for diagnostic and therapeutic interventions and analysis, certain conditions like diabetes mellitus can cause male infertility by more than one mechanism, for example, effect on sperm DNA, increased genital tract infections, coital dysfunction, and retrograde ejaculation. Other factors may cause infertility for a specific period of time; for example, stress and fever hamper spermatogenesis only for a particular period. Common habits of human beings like excess consumption of alcohol leads to increased desire for coitus but decreased performance of the act of coitus. Longterm effects of alcohol decrease the serum concentration of testosterone. Smoking increases carboxyl hemoglobin, which hampers the optimum spermatogenesis.

\section{OBJECTIVES}

To classify the causes of male infertility at pre-testicular, testicular, and post-testicular levels. The pre-testicular causes involve mainly hypothalamus and pituitary. Posttesticular causes mainly involve low obstruction.

\section{MATERIALS AND METHODS}

This study was conducted at the Department of Obstetrics and Gynecology in collaboration with the Department of Radio Diagnosis, Institute of Postgraduate Medical Education and Research, Kolkata. During the study period of 1 year (from August 1, 2009, to July 31, 2010), 
100 male patients attending infertility clinic and outpatient units for the treatment of infertility, and those who had abnormal semen analysis, were evaluated with detailed history-taking, which includes occupational history and any medical disorders like diabetes mellitus, liver disorders, thyroid disorders, or recurrent upper respiratory infections. Any surgical disorders like hernia, hydrocele repair, renal transplant, or scrotal surgeries were also taken into consideration. Personal history related to habits like smoking, alcohol, excess caffeine, and other recreational drugs and marital history related to the psychological well-being of the couple, coital knowledge, and coital dysfunction were also noted. General physical examination for the assessment of pallor, icterus, cyanosis, clubbing, pedal edema, lymph adenopathy, obesity, patient's habitus, the pattern of virilization, the presence or absence of temporal pattern of balding and fine wrinkles, gynecomastia, and situs inverses were noted. Systemic examination and genital examination for systemic or local disorders were done. All patients were subjected to routine investigations followed by semen analysis and those who had abnormal semen analysis on two occasions were evaluated with hormonal assay, transscrotal ultrasound, transscrotal Doppler, and transrectal ultrasound.

\section{RESULTS}

Table 1 in this study, 64\% $(n=64)$ patients were between 25 and 35 years, 31\% $(n=31)$ between 35 and 45 years, and $4 \%(n=4)$ more than 45 years. Only $1 \%(n=1)$ patient was less than 25 years.

In this study, erectile dysfunction was seen in $57.14 \%$ $(n=4)$ of cases, ejaculatory failure due to neural cause in $14.28 \%(n=1)$, and due to drugs in $28.57 \%(n=2)$.

Table 1: Distribution of patients according to age

\begin{tabular}{lll}
\hline Age in years & $n=100$ & $\%$ \\
\hline$<25$ & 1 & 1 \\
$25-35$ & 64 & 64 \\
$>35-45$ & 31 & 31 \\
$>45-55$ & 4 & 4 \\
\hline
\end{tabular}

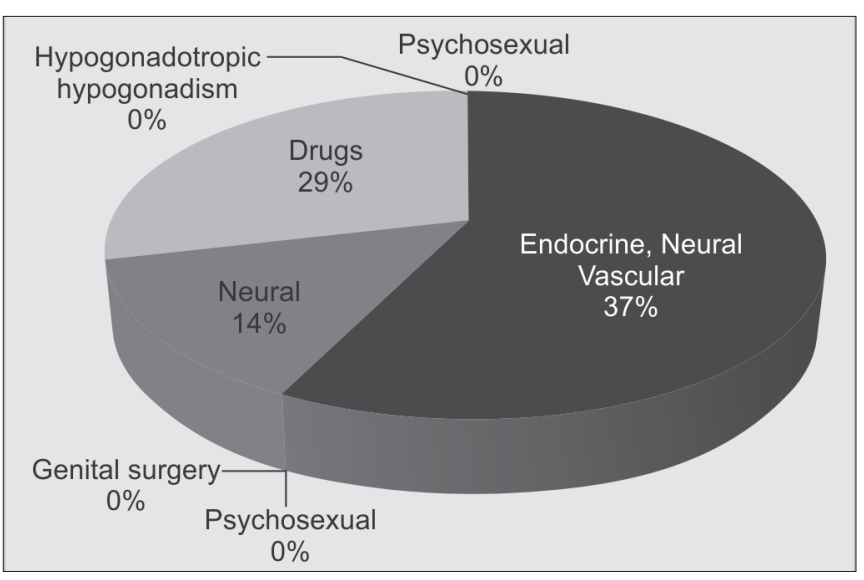

Graph 1: Distribution of pre-testicular causes of male infertility

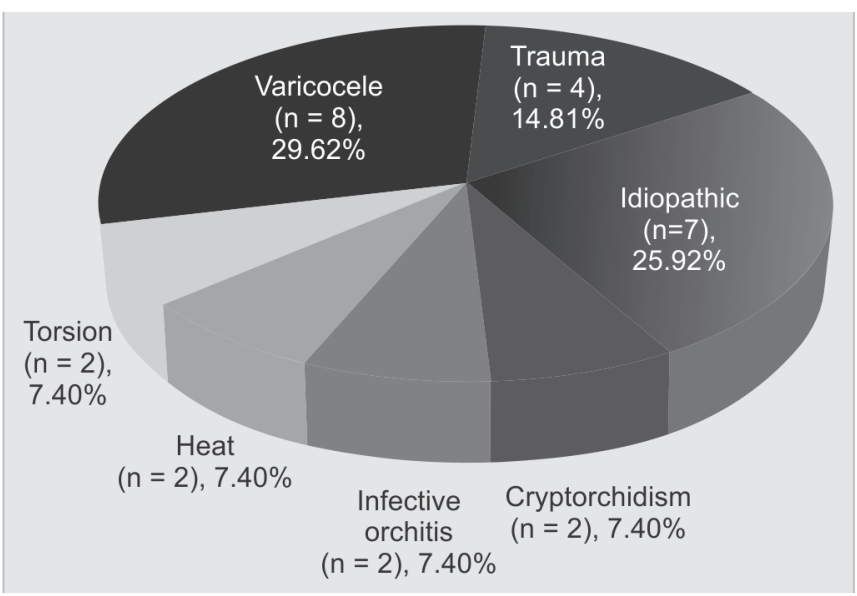

Graph 2: Distribution of testicular causes of male infertility

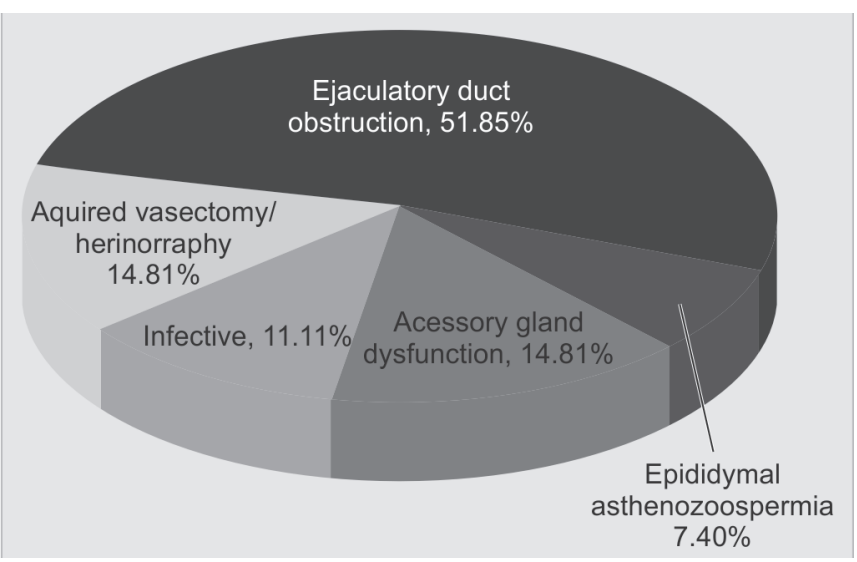

Graph 3: Distribution of post-testicular causes of male infertility

Table 2: Significant past surgical history

\begin{tabular}{llll}
\hline Sl. no. & Surgery & $n=10$ & $\%$ \\
\hline 1 & Herniorrhaphy & 3 & 30 \\
2 & Herniotomy & 1 & 10 \\
3 & Undescended testis & 2 & 20 \\
4 & Torsion & 2 & 20 \\
5 & Hydrocele & 2 & 20 \\
\hline
\end{tabular}

Reports 1-19 describe testicular infertility. In this study, distribution of 27 testicular cases were $25.92 \%$ $(\mathrm{n}=7)$ idiopathic, $29.62 \%(\mathrm{n}=8)$ varicocele, $14.81 \%$ $(\mathrm{n}=4)$ traumatic, $7.40 \%(\mathrm{n}=2)$ torsion, $7.40 \%(\mathrm{n}=2)$ antispermatogenic agents heat, $7.4 \%$ torsion, $7.4 \%(n=2)$ infective orchitis, and $7.4 \%(\mathrm{n}=2)$ cryptorchdism.

In this study, distribution of $27 \%(n=27)$ post-testicular cases were $51.85 \%(n=14)$ ejaculatory duct obstruction, $14.81 \%(n=4)$ accessory gland dysfunction, $14.81 \%(n=4)$ acquired hernia surgeries, $11.11 \%(n=3)$ infective cases, and $7.4 \%(\mathrm{n}=2)$ epididymal asthenozoospermia.

Table 2 in this study, significant past history was seen in $10 \%(n=10)$ patients. Of them, 30\% $(n=3)$ had herniography, $10 \%(\mathrm{n}=1)$ had herniotomy, $20 \%(\mathrm{n}=2)$ had surgery for undescended testis, while torsion was seen in $20 \%(n=2)$ of cases and hydrocele in $20 \%(n=2)$ of cases. 
Table 3: Significant past medical history

\begin{tabular}{llll}
\hline Sl. no. & Medical & $n=12$ & $\%$ \\
\hline 1 & Depression & 4 & 33.33 \\
2 & Tuberculosis & 3 & 25 \\
3 & Malaria & 2 & 16.66 \\
4 & Hypertension & 1 & 8.33 \\
5 & Mumps & 2 & 16.66 \\
\hline
\end{tabular}

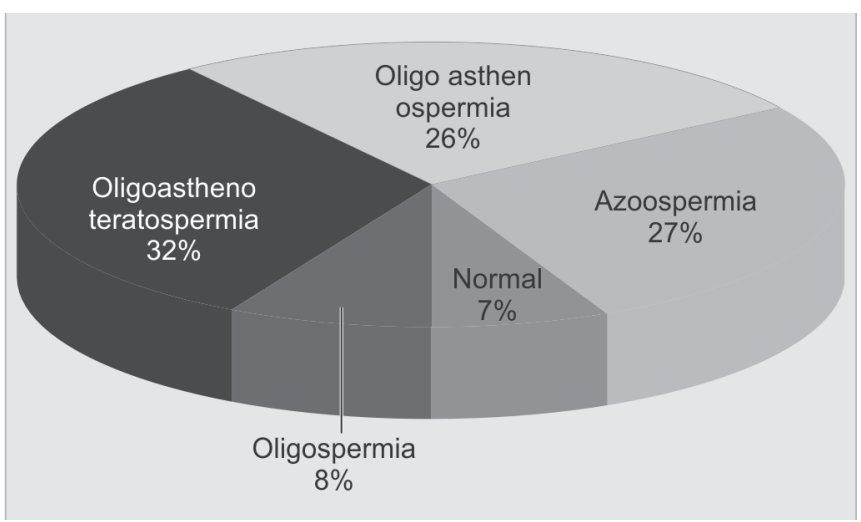

Graph 4: Distributions of seminogram

Table 4: Distribution of the seminal abnormalities in various groups

\begin{tabular}{llllllllll}
\hline & $\begin{array}{l}\text { AZO } \\
(n=27)\end{array}$ & $\%$ & $\begin{array}{l}\text { OLI } \\
(n=8)\end{array}$ & $\%$ & $\begin{array}{l}\text { OA } \\
(n=26)\end{array}$ & $\%$ & $\begin{array}{l}\text { OAT } \\
(n=32)\end{array}$ & $\%$ \\
\hline $\begin{array}{l}\text { Pre- } \\
\text { testicular }\end{array}$ & 1 & 3.7 & 1 & 12.5 & 0 & - & 1 & 3.1 \\
Testicular & 12 & 44.4 & 2 & 25 & 8 & 30.7 & 5 & 15.6 \\
$\begin{array}{l}\text { Post- } \\
\text { testicular }\end{array}$ & 7 & 25.9 & 1 & 12.5 & 9 & 34.6 & 7 & 21.8 \\
Idiopathic & 7 & 25.9 & 4 & 50 & 9 & 34.6 & 19 & 59.3 \\
\hline
\end{tabular}

Table 3 in this study, $12 \%(n=12)$ had significant past history. $33.33 \%(n=4)$ had past medical history of depression, $25 \%(n=3)$ had tuberculosis, $16.66 \%(n=2)$ had malaria, $8.33 \%(\mathrm{n}=1)$ had hypertension, and $16.66 \%$ had mumps.

The chart shows the distribution of the seminogram. In this study OAT was seen in $32 \%(n=32)$ of cases, AZO in $27 \%(\mathrm{n}=27), \mathrm{OA}$ in $26 \%(\mathrm{n}=26)$, and oligospermia in $8 \%$ $(n=8)$ of patients and the result was normal in $7 \%(n=7)$.

The percentages in the table shown are the column percentages.

Table 4 in this study, 3.7\% of the azoospermics $(n=1)$ were in the pre-testicular group, $44.4 \%(\mathrm{n}=12)$ in the testicular group, $25.9 \%(n=7)$ each in the post-testicular and idiopathic groups.

In this study, $50 \%$ of oligospermics $(n=4)$ were in the idiopathic group, $25 \%(n=2)$ in the testicular group, $12.5 \%$ $(n=1)$ each in pre-testicular and post-testicular groups.

In this study, $30.7 \%$ of the OA $(n=8)$ cases were in the testicular group, $34.6 \%(n=9)$ each in post-testicular and idiopathic groups. No cases of OA were found in the pretesticular group.
A total of $3.1 \%(n=1)$ of the OAT cases were in the pre-testicular group, $21.8 \%(\mathrm{n}=7)$ in the post-testicular group, $15.6 \%(n=5)$ in the testicular group, and $59.3 \%$ $(\mathrm{n}=19)$ in the idiopathic group.

\section{DISCUSSION}

Table 1: In this study, $64 \%$ were in the age group 25 to 35 years and $31 \%$ between 35 and 45 years. In one study, less than 25 years age group comprised $1.7 \%$ patients, 26 to 35 years age group $76 \%$, and above 36 years $22 \%{ }^{1}$ A recent meta-analysis of male fertility research published between 1980 and 1999 concluded that increasing age is associated with decreased semen volume, decreased sperm motility, and decreased number of morphologically normal sperm ${ }^{2,3}$ (Kid et al).

Graph 1: In this study, pre-testicular male infertility is $7 \%$, erectile dysfunction attributed for $57.14 \%(n=4)$, and ejaculatory dysfunction $28.5 \%$. As per data from Comhaire et al, sexual/ejaculatory inadequacy comprised 3\%; the Escher Capri workshop group (1994) accounted for $1.7 \%$ sexual factors. ${ }^{4}$

Graph 2: In this study, testicular infertility attributed to $27 \%$ of total infertility and $25.92 \%$ idiopathic, $29.62 \%$ varicocele, $14.81 \%$ traumatic, $7.40 \%$ anti-spermatogenic agents heat, $7.4 \%$ torsion, $7.4 \%$ infective orchitis, and $7.4 \%$ cryptorchdism. According to data from Comhaire et al (1987); the Escher Capri workshop group (1994); and Burkman LJ, Cardington CC, Franken DR, et al (1988); Western Siberian study; and Sudanese study, varicoceles were seen in 13,12.3, 37.4, 11.3, and 22\% respectively. ${ }^{5,6,8-11}$ In the present study varicocele is seen in $29.62 \%$; the prevalence of varicoceles in men presenting with infertility is 20 to $40 \%$ (Dubin and Amelar; Cockett et al; Aafjes and Van Der Vijver; Marks et al). ${ }^{10,11}$ Varicocele is the most common correctable cause of male infertility. Approximately $90 \%$ of varicoceles are left sided. Whereas most studies report an approximately $10 \%$ prevalence of bilateral varicoceles, detrimental effects of varicoceles have included reflux of renal and adrenal metabolites from the renal vein (Comhaire and Vermeulen) ${ }_{1}^{12}$ decreased blood flow (Saypol et al), ${ }^{13}$ and hypoxia (Chakraborty et al). ${ }^{14}$ The work of Burkman LJ, Cardington CC, Franken DR, et al (1988) shows testicular failure in $9.4 \%$, cryptorchism, in $6.1 \%,{ }_{1}^{15}$ and mumps orchitis in $3.6 \%$. In the present study cryptorchism is seen in $7.4 \%$; cryptorchidism is present in 3 to $4 \%$ of fullterm boys. ${ }^{18}$ By 1 year of age, 1 to $1.6 \%$ of boys demonstrate undecided testes (Scorer and Farringdon, cryptorchidism). Sperm concentrations below 12 to 20 million $/ \mathrm{ml}$ are found in $50 \%$ of patients with bilateral cryptorchidism and in approximately $25 \%$ of patients with unilateral cryptorchidism. Increasing evidence points to a defect in the hypothalamic-pituitary-gonadal axis in patients with cryptorchidism (Canlorbe et al). ${ }^{6}$ 
In our study, mumps orchitis is seen in $7.4 \%$ cases. Mumps associated with orchitis is seen in $30 \%$ of patients, the orchitis is bilateral in 10 to $30 \%$ (Beard et al). ${ }^{16}$ Permanent testicular atrophy may develop within several months to several years after infection. This may result in atrophy of the seminiferous tubules. Severe bilateral orchitis may result in hypergonadotropic hypogonadism and gynecomastia. Testicular torsion in the present study is seen in $7.4 \%$ of cases. The severity of the semen abnormalities appears to be directly related to the duration of testicular torsion. The fertility of adults with prepubertal testicular torsion does not appear to be reduced (Pure et al). ${ }^{17,7}$ In the present study, heat exposure is seen in $7.4 \%$ cases. Heat exposure through the use of saunas (Brown-Woodman et al; Sekihan et al) and hot baths (Lue et al) ${ }^{18}$ is shown to have a detrimental effect on semen parameters. Occupations with heat exposure and infertility include bakers, drivers (industrial machinery, taxis, trucks), ceramic oven operators, welders, and workers in submarines (Velez De La Called et al). ${ }^{5}$ In addition, a dysfunction of testicular thermoregulation has been suggested to occur in paraplegic men in wheelchairs (Bindley). ${ }^{19}$ Impaired semen quality and spermatogenesis have resulted from experimental hyperthermia (Procope) ${ }^{20}$

Reports 13,14,15,16,17,20,21 describe posttesticular infertility. Graph 3: In this study, post-testicular infertility attributed was $27 \%, 51.85 \%$ had ejaculatory duct obstruction, $14.81 \%$ had accessory gland dysfunction, $14.81 \%$ had acquired hernia surgeries, $11.11 \%$ infective cases, $7.4 \%$ epididymal asthenozoospermia. No case of immunological, idiopathic, post-vasectomy, or cystic fibrosis was found. In the work of Burk Man LJ, Cobbington CC, Franken DR, et al (1988) ejaculatory duct obstruction was seen in $6.1 \%{ }^{21}$ western Siberia the most frequent cause of male infertility was inflammatory disease of male accessory glands $(12.9 \%) .{ }^{22} \mathrm{WHO}$ bulletin has reported an incidence of, accessory gland dysfunction as $4 \% .{ }^{23}$ In one study accessory gland dysfunction was seen in $13 \%$ cases $(n=271) .{ }^{24}$ Data from Comhaire et al estimate accessory gland infection as $8 \%$, obstructive azoospermia $2.5 \%$, iatrogenic causes $1 \%{ }^{1}$ In this study obstructive azoospermia was seen in $25.9 \%(n=7)$ of cases, iatrogenic causes was seen in $14.81 \%$ of cases. Obstruction of the ductal system is found in 7 to $12 \%$ of all infertile men and is much more common in azoospermic men (Dubin and Amelar; Greenberg et al; Jarow et al). ${ }^{25,26}$ In a study in Sudan, hernia repair and surgery on hydrocele was seen in $6.7 \%$ of cases of infertility; in our study, hernia repair accounted for $14.81 \%$ cases.

Table 2: In this study past surgical history was significant in $10 \%$ of patients, 30\% had herniography, $10 \%$ had herniotomy, $20 \%$ had surgery for undescended testis, and torsion was seen in $20 \%$ of cases. Hydrocele was seen in $20 \%$ of cases. The work of Burkman LJ, Cardington CC, Franken DR, et al showed the incidence of cryptorchism up to $6.1 \%$ and a study in Sudan had incidence of cryptorchism up to $6.7 \% .{ }^{25}$ In another study, orchiedectomy was seen in $2.6 \%$ of cases, herniorgaphy in $2.6 \%$, and other surgeries $20.9 \%{ }^{27}$ Table 3 : In this study, $12 \%$ had significant past medical history attributing to cause of infertility: $33.33 \%$ had depression, $25 \%$ had tuberculosis, $16.66 \%$ had malaria, and $8.33 \%$ had hypertension, and mumps was seen in $16.66 \%$. In one study the systemic illness was seen in $0.2 \%$ cases. ${ }^{3}$ In another study, the systemic disease accounted for $44 \%$ cases. ${ }^{15}$ Antihypertensive medications have frequently been associated with sexual dysfunction. Spironolactone, an aldosterone antagonist that has been associated with sexual dysfunction, also may be detrimental to semen quality through its anti-androgen activity (Tidd et al). ${ }^{3}$ After a febrile illness, spermatogenesis may be impaired for up to 3 months (Buch and Havlovec). ${ }^{28}$

Table 5 and Graph 4: In this study majority of patients had OAT (32\%), followed by azoospermia (27\%), OA $(26 \%)$, and oligospermia (8\%). Majority of azoospermics are in the testicular group (44.4\%), 3.7\% in the pretesticular group, and equal number in post-testicular and testicular groups. $50 \%$ of oligospermics are in idiopathic groups. Majority of OAT are in the pre-testicular group (59.3\% cases), and the least OAT is in the idiopathic group. Post-testicular group had $21.8 \%$ OAT; in testicular group it is $15.6 \%$. In one study, idiopathic azoospermia was seen in $0.5 \%$ cases. ${ }^{3,15}$ In a study at Duhok, Iraq, idiopathic azoospermia was seen in $13 \%,{ }^{27}$ oligoasthenospermia in $20.7 \%{ }^{28}$ In a study in Kuwait, idiopathic oligospermia was seen in $30 \%$ of cases and $50 \%$ of the cases were due to testicular causes. ${ }^{1}$ Testicular oligoasthenospermia is seen in $30.7 \%$ cases in the present study, whereas in Kuwait study it was seen in $50 \%$ cases. $^{1}$

Table 5: Oligoasthenoteratospermia is the most common seminal abnormality (32\% of cases), AZO in $27 \%$ of cases, OA in $26 \%$ of patients, and oligospermia in $8 \%$ of patients. Only $7 \%$ of patients had normal sperms

\begin{tabular}{|c|c|c|c|c|}
\hline Study & Oligoasthenoteratospermia & Azoospermia & Astheniospermia & Oligospermia \\
\hline Mongolia 29 & 1.2 & 20.5 & 7.4 & 11.6 \\
\hline Duhok, Iraq 1 & 20 & 13 & 20 & - \\
\hline Another study 2 & 4 & - & 6 & 6 \\
\hline Kuwait 35 & - & 38 & - & 62 \\
\hline Nigeria 30 & 4 & 3 & - & 15 \\
\hline Present study & 32 & 27 & 26 & 8 \\
\hline
\end{tabular}




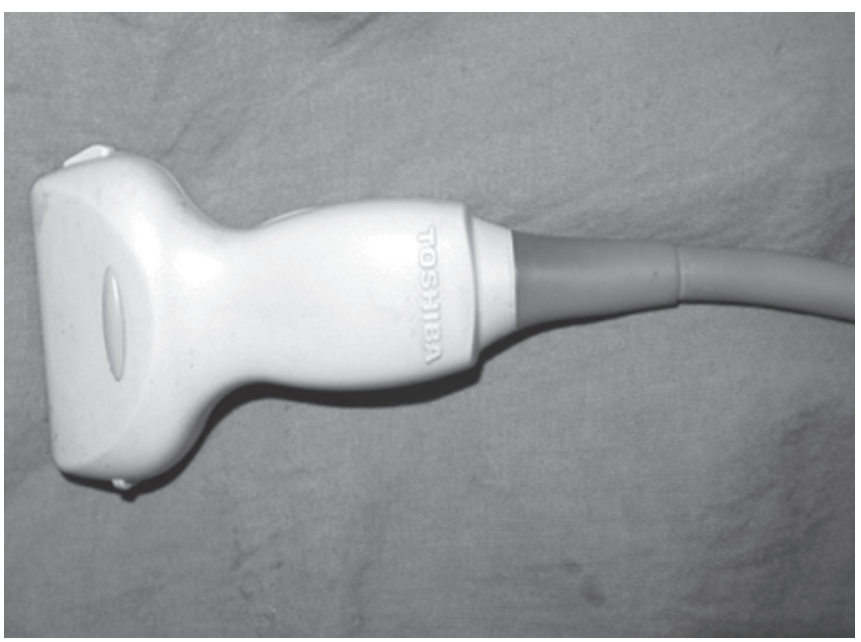

Fig. 1: Transscrotal USG probe

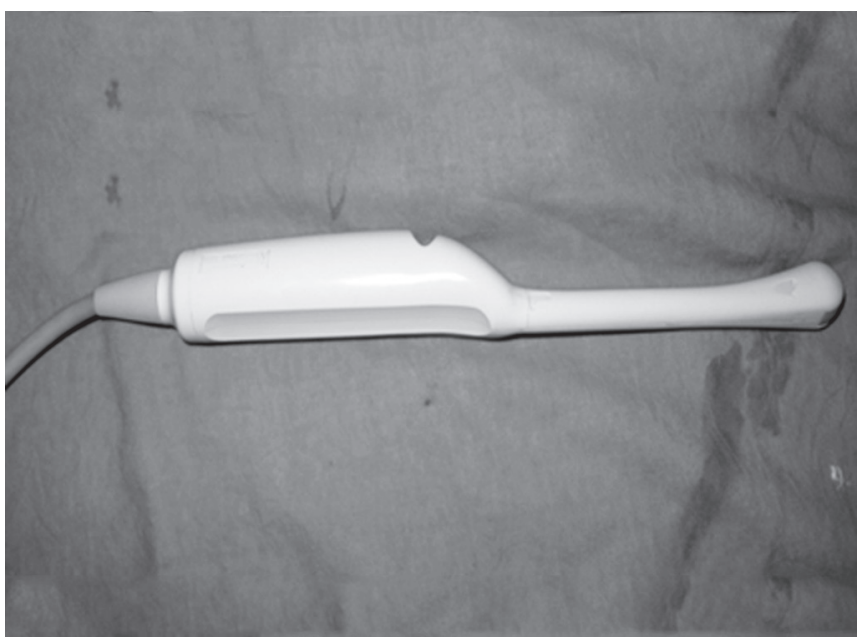

Fig. 3: Transrectal ultrasound probe

\section{SUMMARY}

In this study, majority of the patients are between 25 and 35 years $(58 \%)$, had infertility for 5 to 10 years, past surgical history of herniography in $30 \%$, herinotomy in $10 \%$, and hydrocele excision and torsion cryptorchism contributed for $20 \%$.

The most common past medical disorder is depression $33.33 \%$, tuberculosis in $25 \%$, mumps and malaria both $16.6 \%$, and least common disorder is hypertension in $8.33 \%$,

Pre-testicular cause, is seen in $7 \%$ of patients. Erectile dysfunction is the commonest and the next commonest is ejaculatory failure.

In testicular causes varicocele is the commonest with $29.6 \%$, trauma in $14.8 \%$, and the other causes are torsion, infective orchitis, and cryptorchism shows a common incidence of $7.4 \%$. idiopathic in $25.9 \%$.

In post-testicular varity, $51.8 \%$ cases are due to ejaculatory duct obstruction, accessory gland dysfunction, and acquired hernia surgeries has a common incidence

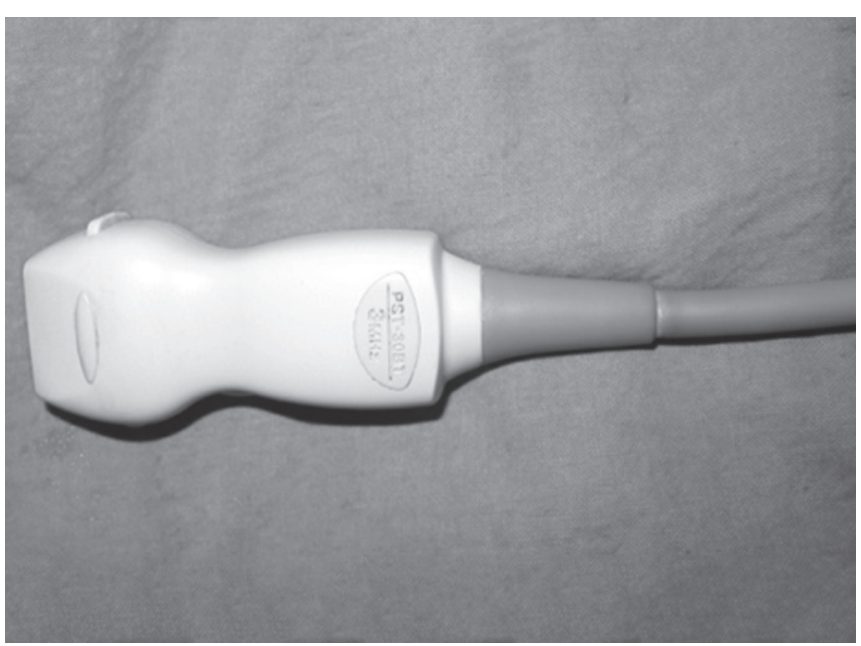

Fig. 2: Transscrotal Doppler probe

of $14.81 \%$. Least common cause is the epididymal asthenozoospermia.

Majority of the azoospermics are in the testicular group, azoospermics are equally distributed in post-testicular and idiopathic groups. A total of 50\% oligospermics are in the idiopathic group, $25 \%$ are in the testicular group, whereas oligospermics are equally distributed in posttesticular and pre-testicular groups. Highest incidence of seminal abnormalities is seen among 25- to 35-year-olds, azoospermia in $51.8 \%$, oligospermia in $65.35 \%$, and OAT in $71 \%$.

Oligoasthenoteratospermia is the most common seminal abnormality in this study; the second most common is azoospermia. Least common is oligospermia.

\section{CONCLUSION}

- In male infertility evaluation history and clinical examination, semen analysis is the most common tool for all groups of patients.

- Pre-testicular male infertile is mainly due to consequences of primary or secondary dysfunction of endocrine or exocrine glands influencing the male reproductive axis. But this group can also be influenced by many iatrogenic medical and surgical interventions.

- In testicular group, male infertility is due to varity of genetic, congenital, and acquired insults to the proper testicular function. This group of patients are evaluated by serum FSH, serum testosterone, transscrotal ultrasound, and transscrotal Doppler Figs 1 and 2. This group is influenced by the occupational and personal habits of patients.

- Post-testicular cause of infertility are due to pathology in the pathway of sperm passage. This is influenced by congenital and acquired defects and diseases respectively. Further, there are conditions that are 


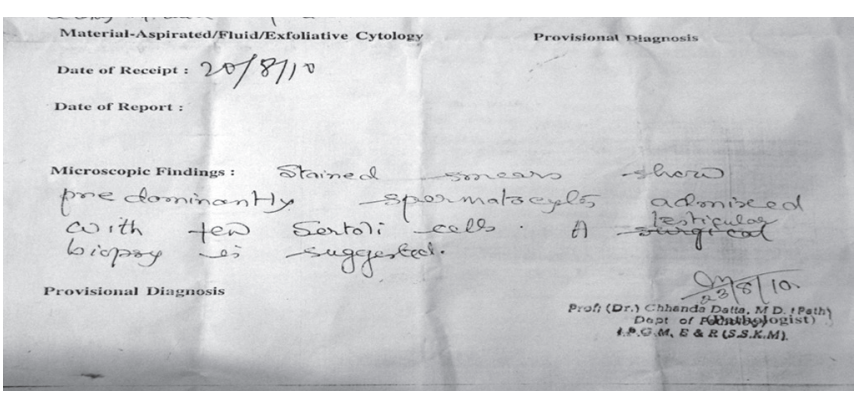

Report 1: Fine needle aspiration cytology report of the testis showing the spermatocytes with few sertoli cells

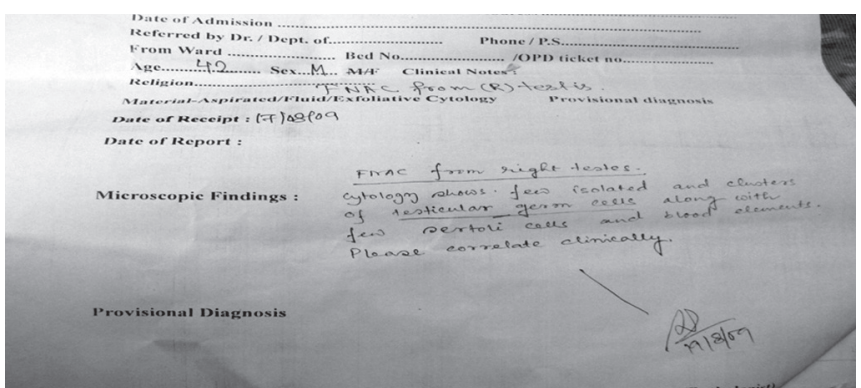

Report 2: Fine needle aspiration cytology report of the right testis showing the few isolated and clusters of testicular germ cells along with sertoli cells and blood elements

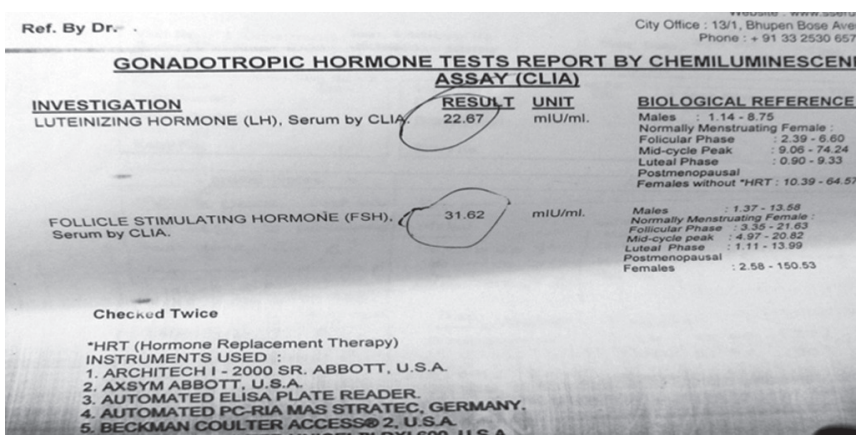

Report 4: The elevated FSH and LH in case of testicular failure

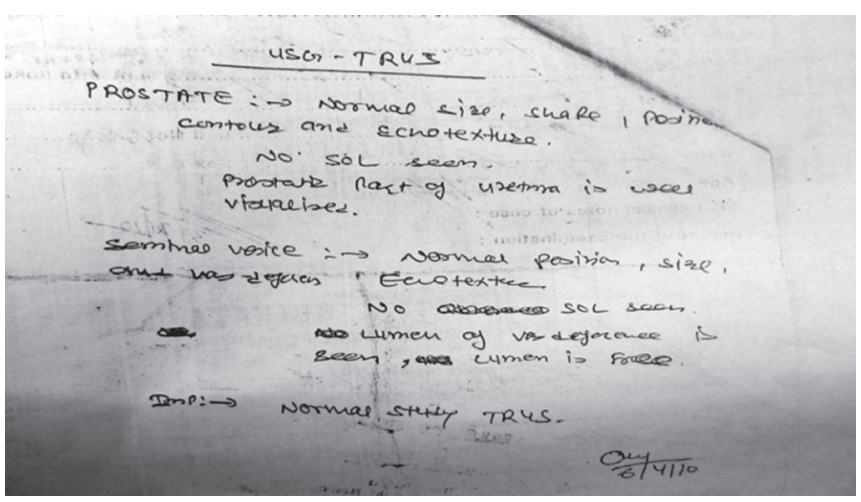

Report 6: Report of TRUS showing normal study

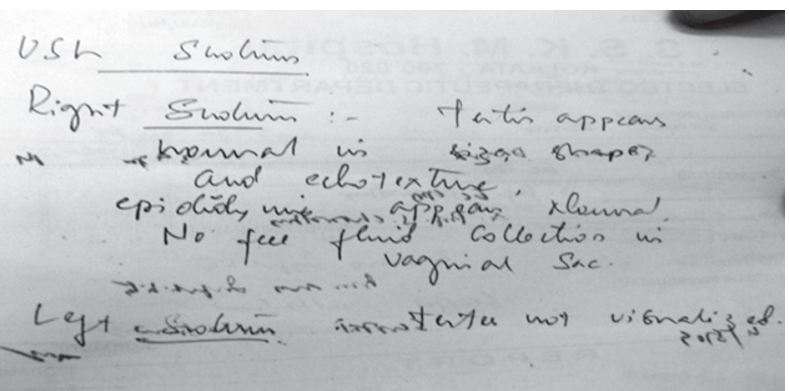

Report 8: The transscrotal ultrasonography showing nonvisualization of left testis

hostile for sperm motility and maturation. The main tool in this group is the TRUS (Fig. 3).

- The idiopathic group of patients need further evaluation by use of advanced seminal tests like
Report 7: The report of transscrotal ultrasonography showing bilateral testicular microlithiasis with right-sided epididymal cyst from the body 


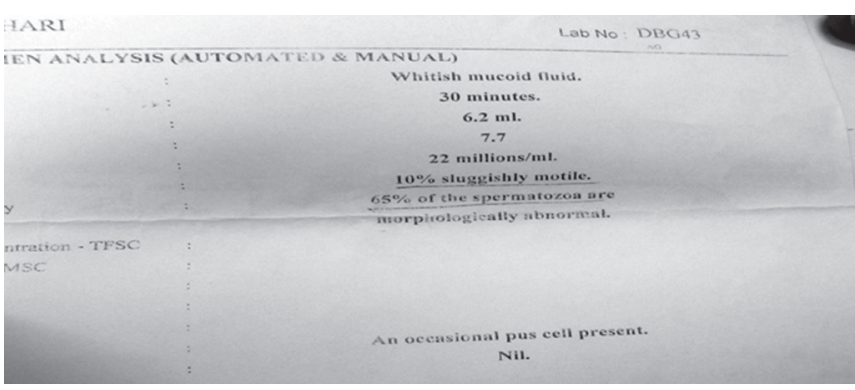

Report 9: Seminogram showing asthenospermia due to $65 \%$ abnormal sperms

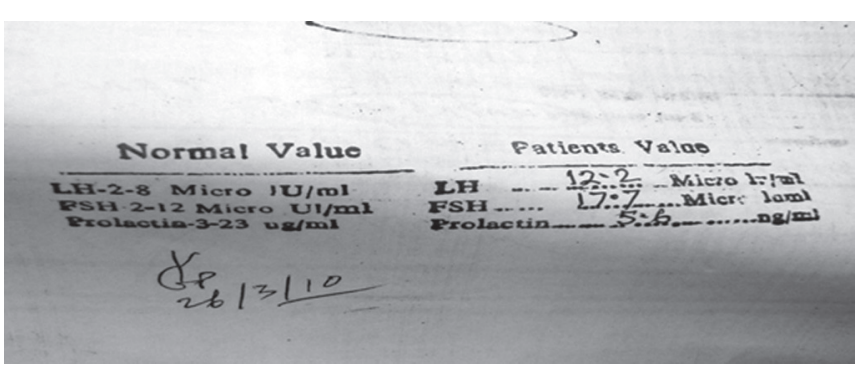

Report 11: Report showing the elevated FSH and LH in case of bilateral testicular microlithiasis with azoospermia

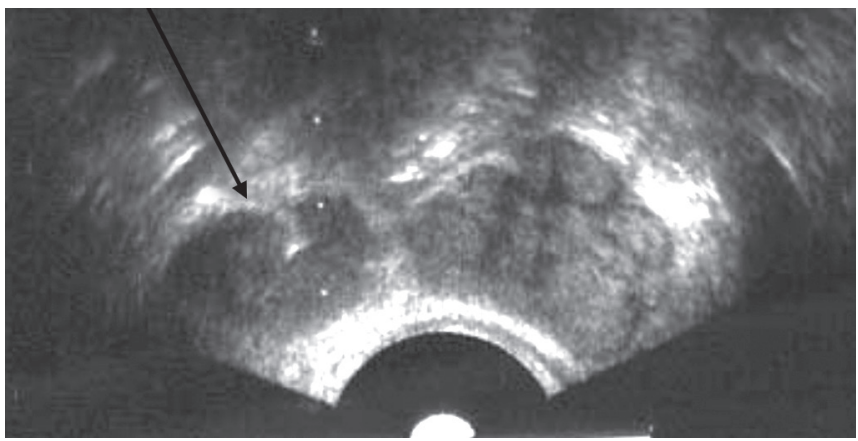

Report 13: Transscrotal ultrasonogram report showing seminal vesical cyst

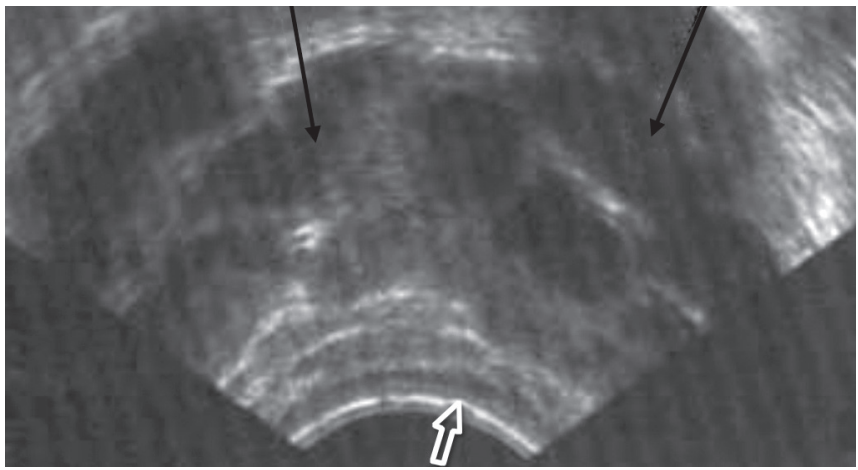

Report 15: Transscrotal ultrasonogram showing the enlargement of seminal vesicals and ejaculatory duct enlargement

immunological tests, semen culture, special staining of the spermatozoa, sperm DNA integrity tests, and appropriate genetic evaluation. Evaluation of ultrastructural abnormalities of spermatozoa. For detection of defects in outer dense fibers, microtubules, mitochondria, connecting piece, and acrosome.

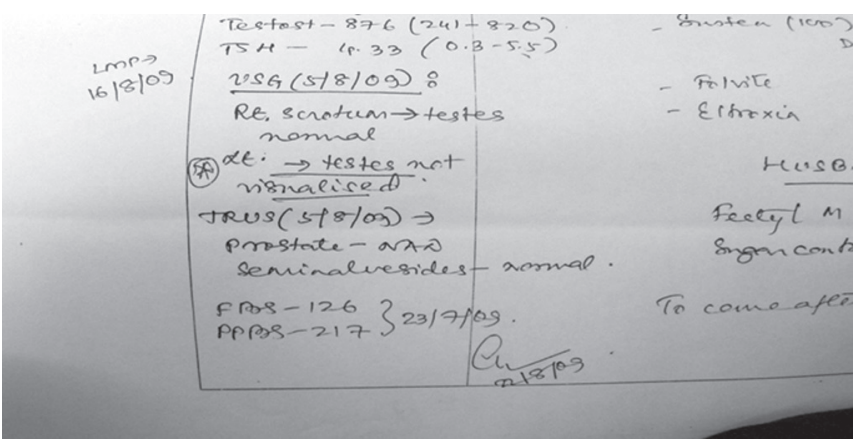

Report 10: History showing the report of nonvisualization of left testis on ultrasound

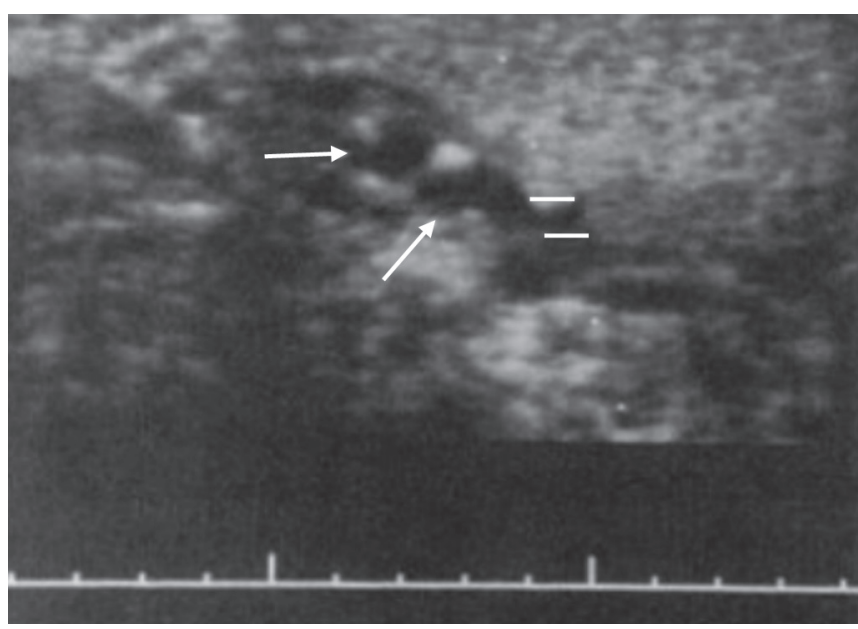

Report 12: Report of scrotal ultrasonogram showing varicocele

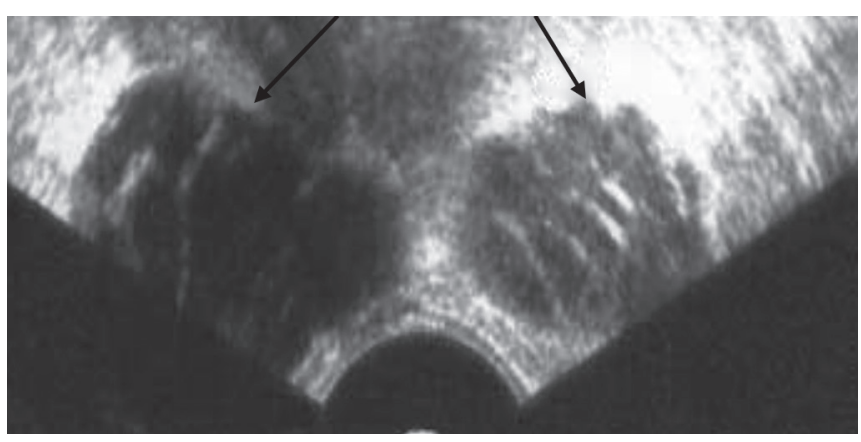

Report 14: Transscrotal ultrasonogram showing bilateral seminal vesical enlargement

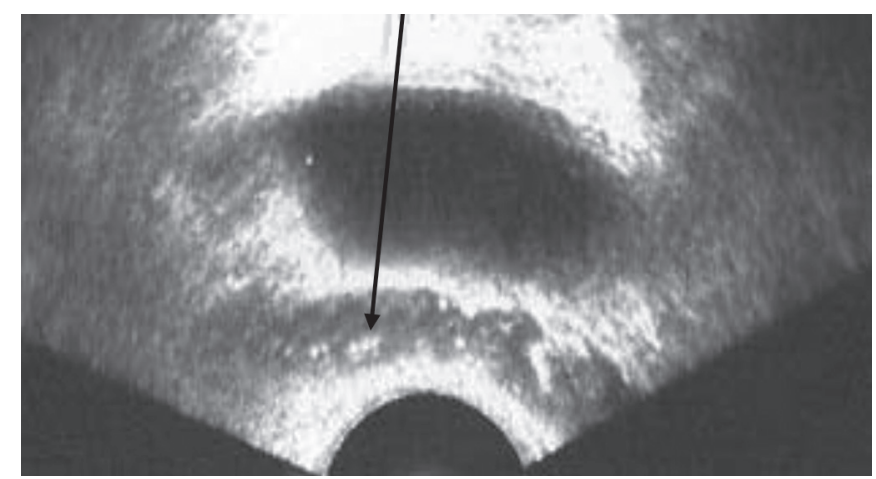

Report 16: Transscrotal ultrasonogram showing seminal vesical calcification 


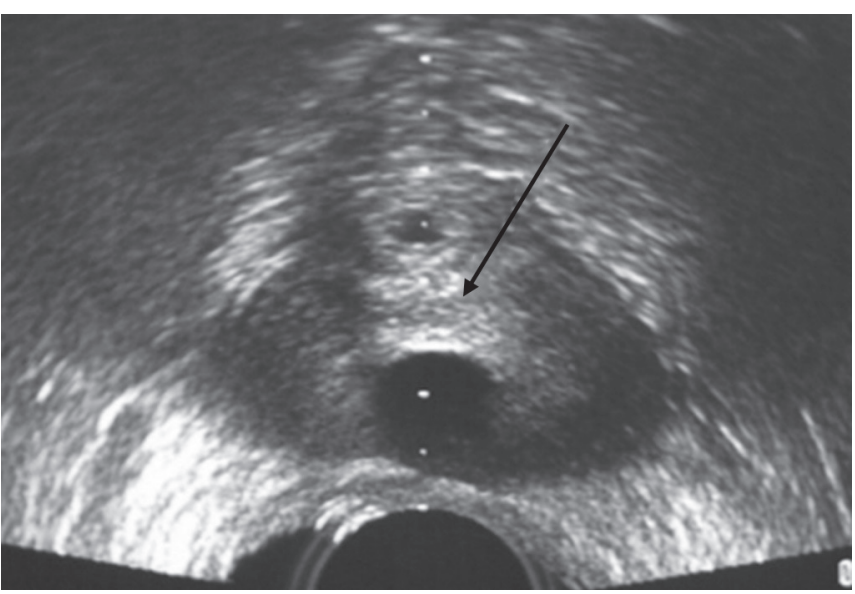

Report 17: Transscrotal ultrasonogram showing large midline cyst

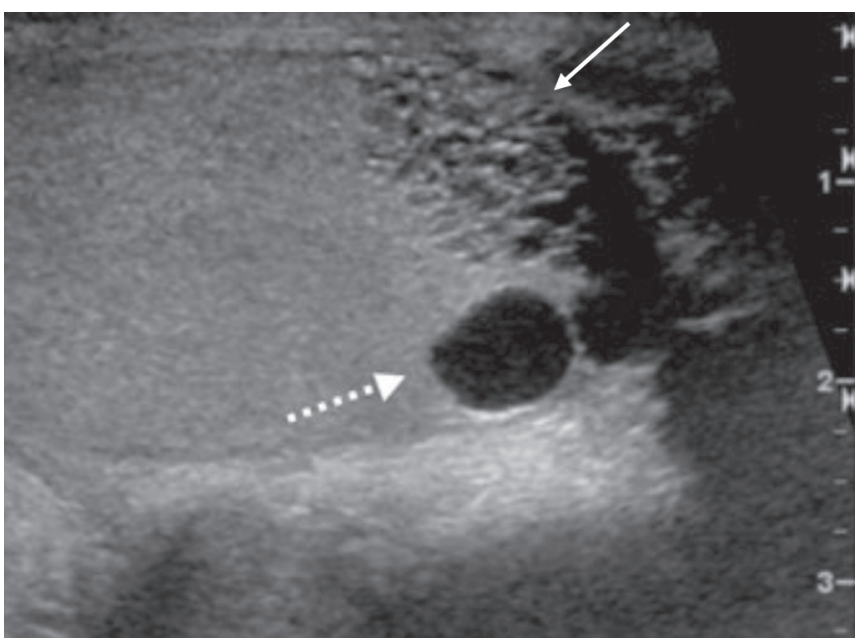

Report 19: Transscrotal ultrasound showing intratesticular cyst in a patient with azoospermia

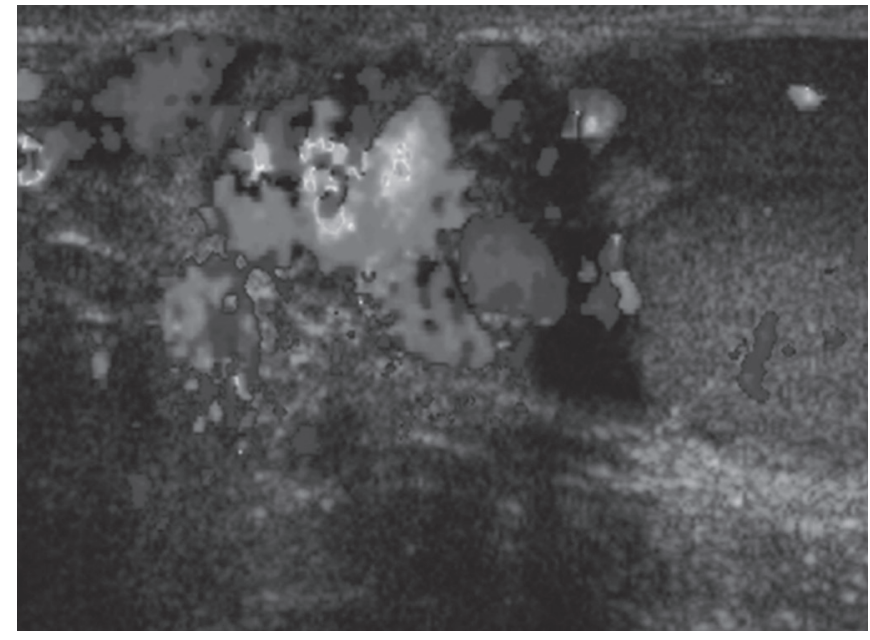

Report 21: Transscrotal Doppler of left hemiscrotum shows multiple dilated peri-testicular veins on color Doppler imaging

\section{PROFORMA}

\section{A. History}

- DATE:

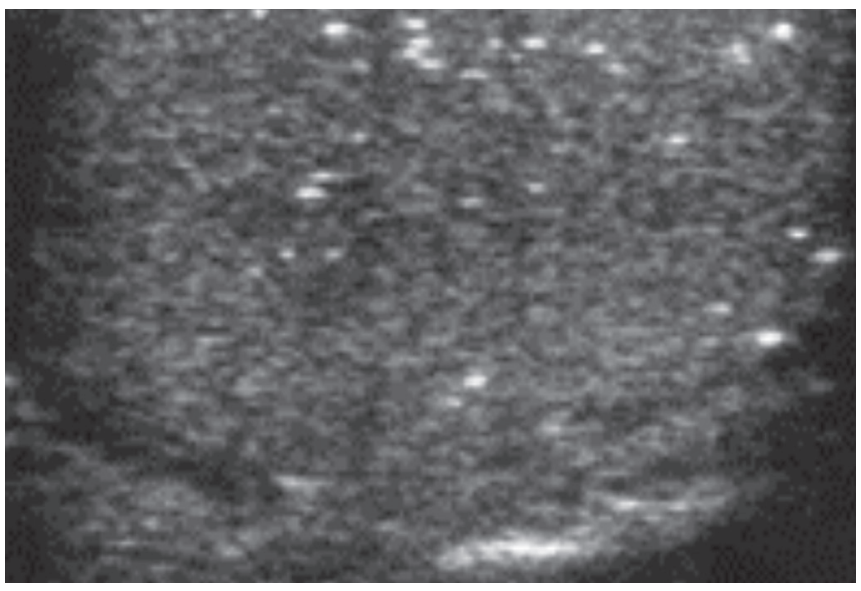

Report 18: Transscrotal ultrasonogram showing testicular microlithiasis

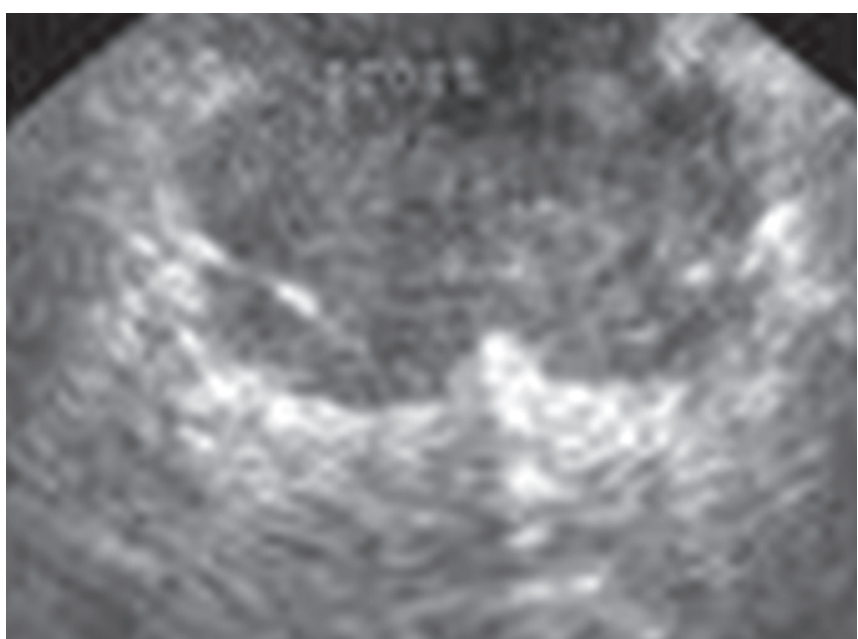

Report 20: Transscrotal ultrasonogram showing enlarged seminal vesicals

- REGISTRATION NO:

- SERIAL NO:

- NAME:

- AGE:

- SOCIOECONOMIC STATUS:

- DURATION OF INFERTILITY:

- OCCUPATIONAL HISTORY:

- CHILDHOOD HISTORY:

- MEDICAL HISTORY:

- SURGICAL HISTORY:

- PERSONAL HISTORY: HABITS - SMOKING, ALCOHOL, TOBACOO CHEWING.

- MARITAL HISTORY:

- DRUG HISTORY:

\section{B. General physical examination}

- PALLOR:

- ICTERUS:

- CYANOSIS:

- CLUBBING:

- PEDAL EDEMA: 
- LYMPH ADENOPATHY:

- OBESITY:

- BLOOD PRESSURE:

- GYNECOMASTIA:

- PATIENT'S HABITUS, THE PATTERN OF VIRILIZATION, PRESENCE OR ABSENCE OF TEMPORAL PATTERN BALDING AND FINE WRINKLES, GYNECOMASTIA, SITUS INVERSES ARE NOTED.

\section{Systemic examination}

- CARDIOVASCULAR SYSTEM:

- RESPIRATORY SYSTEM:

- ABDOMINAL EXAMINATION:

- CENTRAL NERVOUS SYSTEM EXAMINATION:

\section{Genital examination}

- PENIS

- SCROTUM

- TESTIS:

- TRAN-ILLUMINATION DONE FOR ALL SCROTAL MASSES:

- EPIDIDYMIS:

- SPERMATIC CORD AND VAS DEFERENS:

- testicular tUNiCs AND ADNEXA HYDROCELES:

\section{Rectal examination}

- ESTIMATION OF SPHINCTER TONE IS.

- DIGITAL PROSTATIC EXAMINATION OF SIZE, CONSISTENCY, TENDERNESS, MOBILITY.

\section{TESTING PER ANAL SENSATION}

\section{E. Investigations}

- SEMEN ANALYSIS:

- BL.HB\%: TC: DC: ESR: AT 1 HR

- FBS:

- PPBS:

- SERUM CREATININE:

- UREA:

- VDRL:

- HBSAG:

- VCTC:

- LFT:

- URINE RE/ME:

- S.TSH:

- S.TESTOSTERONE:

- LH:

- FSH:

- PROLACTIN:
- Transrectal USG:

- Transscrotal USG:

- Transscrotal DOPPLER:

\section{Additional investigations (as applicable)}

- KARYOTYPING:

- VASOGAPHY:

\section{REFERENCES}

1. Razzak AH, Wais SA. The infertile couple, a cohort study in Duhok, Iraq. East Mediterr Health J 2002 Mar-May;8(2-3): 234-238.

2. Sigman M, Jarrow JP. Chapter 19: Male infertility. In: Text book of urology, the Campbell-Walsh urology. 9th ed., Vol. 1. Philadelphia: Saunders Elsevier; 2007.

3. Morley L, Rutherford A. Literatures of male infertility. Student BMJ 2008;16:368-369.

4. ESHER Capri Workshop Group. Male sterility and sub fertility guidelines for management. Hum Reprod 1994 Jul;9(7): 1260-1264.

5. Burkman LJ, Coddington CC, Franken DR, Krugen TF, Rosenwaks Z, Hogen GD. The hemizona assay (HZA): Development of a diagnostic test for the binding of human spermatozoa to the human hemizona pellucida to predict fertilization potential. Fertil Steril 1988 Apr;49(4):688-697.

6. Ahmed MEIM, Mansour MM, Khalid KE, Yosif N, Elhasan EM, Miskeen E. Semen analysis of infertile Sudanese males in Gezira state central Sudan. Sudanese J Public Health 2009 Apr;4(3):342.

7. Puri P, Barton D, O'Donnell B. Prepubertal testicular torsion: Subsequent fertility. J Pediatr Surg 1985 Dec;20(6):598-601.

8. Dubin L, Amelar RD. Varicocelectomy: 986 cases in a 12-year study. Urology 1977 Nov;10(5):446-449.

9. Marks JL, McMahon R, Lipshultz LI. Predictive parameters of successful varicocele repair. J Urol 1986 Sep;136(3):609-612.

10. Saypol DC, Howards SS, Turner TT, Miller ED Jr. Influence of surgically induced varicocele on testicular blood flow, temperature, and histology in adult rats and dogs. J Clin Invest 1981 Jul;68(1):39-45.

11. Chakraborty J, Hikim AP, Jhunjhunwala JS. Stagnation of blood in the microcirculatory vessels in the testes of men with varicocele. J Androl 1985 Mar-Apr;6(2):117-126.

12. Lue $\mathrm{YH}$, Lasley BL, Laughlin LS, Swerdloff RS, Hikim AP, Leung A, Overstreet JW, Wang C. Mild testicular hyperthermia induces profound transitional spermatogenic suppression through increased germ cell apoptosis in adult cynomolgus monkeys (Macaca fascicularis). J Androl 2002 Nov-Dec;23(6): 799-805.

13. Telisman S, Cvitković P, Jurasović J, Pizent A, Gavella M, Rocić B. Semen quality and reproductive endocrine function in relation to biomarkers of lead, cadmium, zinc, and copper in men. Environ Health Perspect 2000 Jan;108(1):45-53.

14. Brindley GS. Deep scrotal temperature and the effect on it of clothing, air temperature, activity, posture, and paraplegia. Br J Urol 1982 Feb;54(1):49-55.

15. PhilippovOS, RadionchenkoAA, Bolotova VP, VoronovskayaNI, Potemkina TV. Estimation of the prevalence and causes of infertility in WesternSiberia. Bull World Health Organ 1998;76(2): 183-187. 
16. Procopé BJ. Effect of repeated increase of body temperature on human sperm cells. Int J Fertil 1965 Oct-Dec;10(4): 333-339.

17. Comhaire F, Vermeulen A. Varicocele sterility: Cortisol and catecholamines. Fertil Steril 1974 Jan;25(1):88-95.

18. Scorer CG, Farrington GH. Congenital deformities of the testis and epididymis. London: Butterworths; 1971.

19. Chang PL, Sauer MV, Brown S. Y chromosome microdeletion in a father and his four infertile sons. Hum Reprod 1999 Nov;14(11):2689-2694.

20. Adiga SK, Jayaraman V, Kalthur G, Upadhya D, Kumar P. Declining semen quality among south Indian infertile men: A retrospective study. J Hum Reprod Sci 2008 Jan;1(1):15-18.

21. Dubin L, Amelar RD. Etiologic factors in 1294 consecutive cases of male infertility. Fertil Steril 1971 Aug;22(8):469-474.

22. Matsuda T, Horii Y, Yoshida O. Unilateral obstruction of the vas deferens caused by childhood inguinal herniorrhaphy in male infertility patients. Fertil Steril 1992 Sep;58(3): 609-613.
23. Carter JN, Tyson JE, Tolis G, Van Vliet S, Faiman C, Friesen HG. Prolactin-screening tumors and hypogonadism in 22 men. N Engl J Med 1978 Oct 19;299(16):847-852.

24. Fakhrildin MBMR. Correlation between seminal fluid analysis and levels of gonadotropins in serum and seminal plasma of normozoospermic men and infertile patients. Iranian J Fertil Steril 2007 Summer;1(2):55-62.

25. Sigman M, Jarrow JP. Chapter 19: Male infertility. In: Wein AJ, editor. Text book of urology, the Campbell-Walsh urology. 9th ed., Vol. 1. Philadelphia: Saunders Elsevier; 2007.

26. Qadan LR, Ahmed AA, Kapila KA, Hassan NA, Kodaj JA, Pathan SK. Male infertility in Kuwait. Saudi Med J 2007 Jan;28(1):96-99.

27. Akinola OI, Fabamwo AO, Rabiu KA, Akinoso OA. Semen quality in male partners of infertile couples in Lagos Nigeria. Int J Trop Med 2010;5(2):37-39.

28. Jiro G, Koichiro N, Shigehiko K, Hiroshi K, Yasuyuki K, Morishi Y. Clinical study of male infertility. Nishinihon J Urol 2002;64(12):687-691. 